\title{
Using Poly-L-Histidine Modified Glassy Carbon Electrode to Trace Hydroquinone in the Sewage Water
}

\author{
Bin Wang and Jun Steed Huang \\ Third Department, Suqian College, Jiangsu 223800, China \\ Correspondence should be addressed to Jun Steed Huang; steedhuang@ujs.edu.cn
}

Received 16 March 2014; Revised 28 July 2014; Accepted 25 August 2014; Published 8 September 2014

Academic Editor: María Isabel Pividori

Copyright ( 2014 B. Wang and J. S. Huang. This is an open access article distributed under the Creative Commons Attribution License, which permits unrestricted use, distribution, and reproduction in any medium, provided the original work is properly cited.

\begin{abstract}
A sensitive voltammetric method for trace measurements of hydroquinone in the sewage water is described. The poly-L-histidine is prepared to modify the glassy carbon electrode in order to improve the electrochemical catalysis of interesting substances such as hydroquinone. The influence of the base solution, $\mathrm{pH}$ value, and scanning speed on the tracing of hydroquinone is discussed, and the experimental procedures and conditions are optimized. The laboratory results show that it is possible to construct a linear calibration curve between the peak current of hydroquinone on modified electrode and its concentration at the level of $0.00001 \mathrm{~mol} / \mathrm{L}$. The potential limitation of the method is suggested by a linear peaking shift model as well. The method was successfully applied to the determination of hydroquinone in the actual sample of industrial waste water.
\end{abstract}

\section{Introduction}

Hydroquinone (1,4-HQ) is a derivative of phenol, mainly used for black and white photographic developers, dyes, rubber antioxidants, earlier skin lightening cream, and so on [1]. Unfortunately the hydroquinone may induce apoptosis of hematopoietic stem cells and immune cells [2-5], which means that it is actually toxic to the body. The determination of the present of hydroquinone is of significance in physiology, medicine, and environment protection. Therefore, it is necessary to establish a rapid, convenient, and accurate method to determine its contamination levels. The commonly used detection methods include complicated gas chromatography-mass spectrometry [6], high performance liquid chromatography [7], flow injection chemiluminescence method [8], thin layer chromatography [9], spectrophotometry [10-12], fluorescence [13,14], and electrochemical method $[15,16]$. Comparing with above mentioned alternatives, electrochemical method has some obvious advantages, such as simple operation, high selectivity, and sensitivity. Currently, most electrochemical methods for hydroquinone determination are based on nanosensors. For example, nonsilver [17], nanoparticles $\mathrm{La}(\mathrm{OH})_{3}$ [18], and nanocarbon electrode [19] have been successfully applied in the quantitative determination of hydroquinone. However, biological molecules modified electrodes, in particular amino acid modified electrodes, are seldom used to detect hydroquinone. Among these, the using of poly-L-histidine modified electrode to determine the hydroquinone level has not been reported yet. Note that the histidine among all the amino acids is the one responsible for passing biological signals across the growing cell membrane; the interaction between the histidine and the hydroquinone is worth further investigations. In this paper, we use cyclic voltammetric method to get poly-Lhistidine modified onto the surface of glassy carbon electrode in order to tune the sensor for the maximum performance. We also study the electrochemical behavior of hydroquinone with the electrode and implement the quantitative tracing method and finally suggest a linear mathematical model for saving the amount of total laboratory time, by predicting the potential limit of outcomes. The measurement results are cross-checked with standard UV spectroscope.

\section{Experiment}

2.1. Experimental Reagent. Histidine and hydroquinone are purchased from Shanghai Chemical Reagent factory; histidine solution $\left(2.5 \times 10^{-3} \mathrm{~mol} / \mathrm{L}\right)$ is stored in the refrigerator 


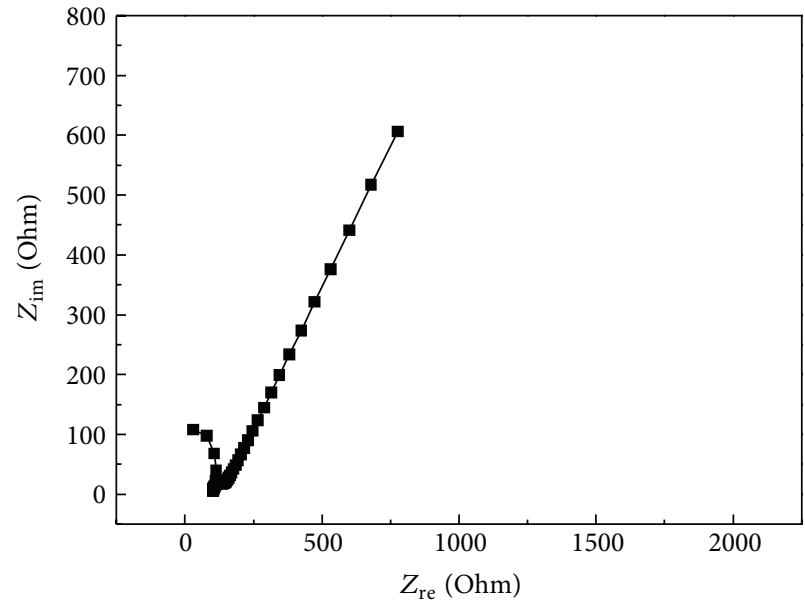

(a)

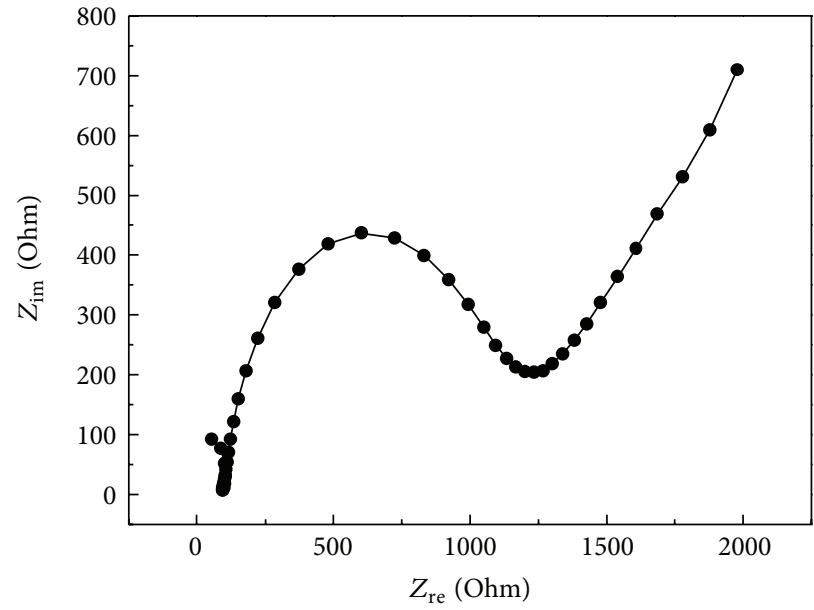

(b)

FIGURE 1: (a) GCE alternating current impedance diagram. (b) PLH/GCE alternating current impedance diagram.

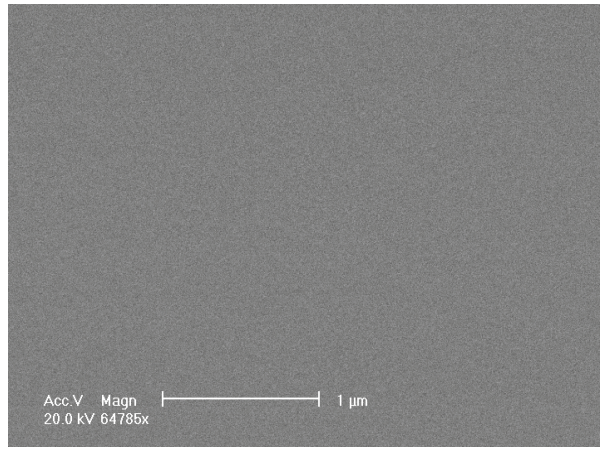

(a)

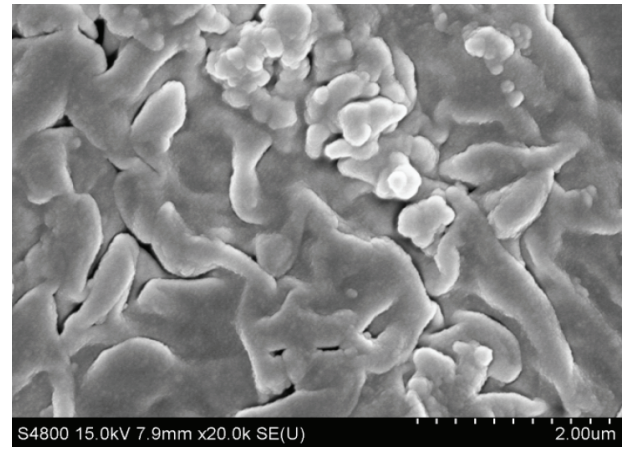

(b)

Figure 2: (a) GCE scanning electron microscopy. (b) PLH/GCE scanning electron microscopy.

$\left(<4^{\circ} \mathrm{C}\right)$; other reagents are analytically pure. All the solutions are prepared with peroxide double-distilled water. The experiment is conducted at room temperature $\left(21^{\circ} \mathrm{C}\right)$.

2.2. The Preparation of Poly-L-Histidine Modified Electrode. First of all, smooth the surface of glassy carbon electrode (GCE) on metallographic sandpaper within \#1 \#7 progressively and then polish it with hyperfine $\mathrm{Al}_{2} \mathrm{O}_{3}$ suspension on silk with radius of $0.3 \mu \mathrm{m}$ and $0.05 \mu \mathrm{m}$. After each polishing, wash the electrode surface with deionized water and then ultrasonically clean it for 2 3 minutes. Repeat this step for three times. Finally, ultrasonically clean it with 1:1 HCl solution, anhydrous ethanol, and double-distilled water, respectively, for 5 minutes. Use platinum electrodes as counter electrodes, processed glassy carbon electrodes as the working electrodes, and saturated calomel electrodes as reference electrodes to compose three-electrode system. Put the three-electrode system in $0.5 \mathrm{~mol} / \mathrm{L} \mathrm{H}_{2} \mathrm{SO}_{4}$ solution at $-0.5 \mathrm{~V} \sim+1.6 \mathrm{~V}$ potential window, and cyclically scan it until it is stable with a scanning speed of $50 \mathrm{mV} / \mathrm{s}$. Set the processed electrodes in double-distilled water for future use.

Set the above three-electrode system at $0.0025 \mathrm{~mol} / \mathrm{L}$ histidine phosphate buffer solution $(\mathrm{pH}=7.0$, concentration $=0.2 \mathrm{~mol} / \mathrm{L}$ ) within the potential range of $-1.2 \sim 2.0 \mathrm{~V}$.
Polymerize it for 15 laps with the electrochemical scanning rate of $50 \mathrm{mV} / \mathrm{s}$. Then take it out to dry and finally get the poly-L-histidine (PLH) modified electrodes ready for use.

2.3. Characterization of PLH Modified Electrode. Impedance is an important parameter that is used to describe the surface properties and electrochemical impedance method can be easily used to analyze the stability of modified electrode membrane. Figure 1(a) is the impedance spectrum of bare glassy carbon electrode in aqueous potassium ferricyanide solution. The figure shows part of semicircle and Warburg straight line, which indicates that the electronic transmission block of GCE is small. Figure $1(\mathrm{~b})$ is the electrochemical impedance spectrum of PLH/GCE electrode in the same $\mathrm{Fe}(\mathrm{CN})_{6}{ }^{3-}$ aqueous solution. Compared with bare glassy carbon electrode, when PLH/GCE assembled completely, the impedance increases and Warburg line disappears, which indicates that the existence of the PLH polymerized membrane prevents the transmission of electron on electrode surface, as well as the successful preparation of PLH/GCE electrode.

Figures 2(a) and 2(b) show the scanning electron microscopy images of GCE and PLH/GCE. From Figure 2(b), we can see that PLH formed some complicated 3D fiber structure 


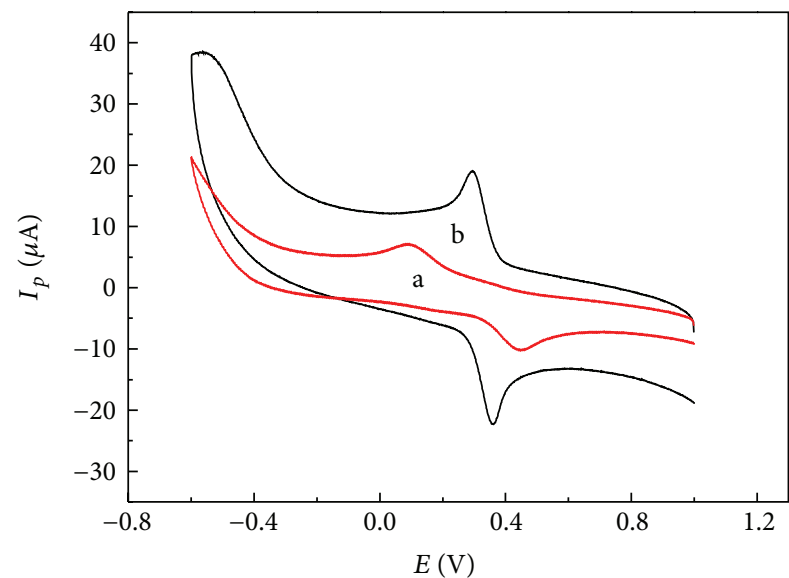

FIGURE 3: Cyclic voltammogram of bare glassy carbon electrode (Curve a) and poly-L-histidine modified electrode (Curve b).

onto the GCH. This fiber structure will dilate in the solution and ease the electron passing to and from the substance to be detected.

2.4. Electric Catalytic Performance of Poly-L-Histidine Modified Electrode on Hydroquinone. Figure 3 indicates that the scanning curve a can be obtained from GCE electrode in $1.0 \times 10^{-4} \mathrm{~mol} / \mathrm{L}$ hydroquinone standard $\mathrm{H}_{2} \mathrm{SO}_{4}(\mathrm{pH}=3.0)$ solution via cyclic voltammetry scanning. A small oxidation peak appears at $0.447 \mathrm{~V}$, and a reduction peak appears at $0.089 \mathrm{~V}$. Curve $\mathrm{b}$ is obtained from poly-L-histidine modified electrodes in standard $\mathrm{H}_{2} \mathrm{SO}_{4}(\mathrm{pH}=3.0)$ solution which contains $1.0 \times 10^{-4} \mathrm{~mol} / \mathrm{L}$ hydroquinone via cyclic voltammetry scanning. A pair of redox peaks appear at $0.362 \mathrm{~V}$ and $0.295 \mathrm{~V}$, with $\Delta \mathrm{E}$ equal to $0.067 \mathrm{~V}$. Compare Curve a and Curve $b$, the potential of oxidation peak in Curve $b$ shifts negatively while the potential of reduction peak shifts positively. Furthermore, the difference between oxidation peak potential and reduction peak potential decreases rapidly which reduces the overpotential, improves the reaction reversibility, and increases the peak current significantly. Figure 4 is the differential pulse voltammetry, from which we see the response current of hydroquinone increasing from just GCE to PLH/GCE. The above phenomenon indicates that poly-L-histidine modified electrode produced electrochemical catalytic effects to hydroquinone. We believe that it is due to the hydrogen bonding interaction between oxygen atoms on carboxyl $\left(-\mathrm{COO}^{-}\right)$of poly-L-histidine, the nitrogen atom on amidogen $\left(-\mathrm{NH}_{2}\right)$, and hydrogen of hydroquinone. This makes the hydroquinone electrochemical reaction on the surface of modified electrodes more easy. The underlying processes are as follows:

$$
\begin{gathered}
\frac{\mathrm{PLH}}{\mathrm{GCE}}+\mathrm{HQ} \longrightarrow \frac{\mathrm{PLH}}{\mathrm{GCE}} \cdot \mathrm{HQ}, \\
\frac{\mathrm{PLH}}{\mathrm{GCE}} \cdot \mathrm{HQ} \longrightarrow \frac{\mathrm{PLH}}{\mathrm{GCE}} \cdot \mathrm{p}-\text { Benzoquinone, } \\
\frac{\mathrm{PLH}}{\mathrm{GCE}} \cdot \mathrm{p}-\text { Benzoquinone } \longrightarrow \frac{\mathrm{PLH}}{\mathrm{GCE}}+\mathrm{HQ} .
\end{gathered}
$$

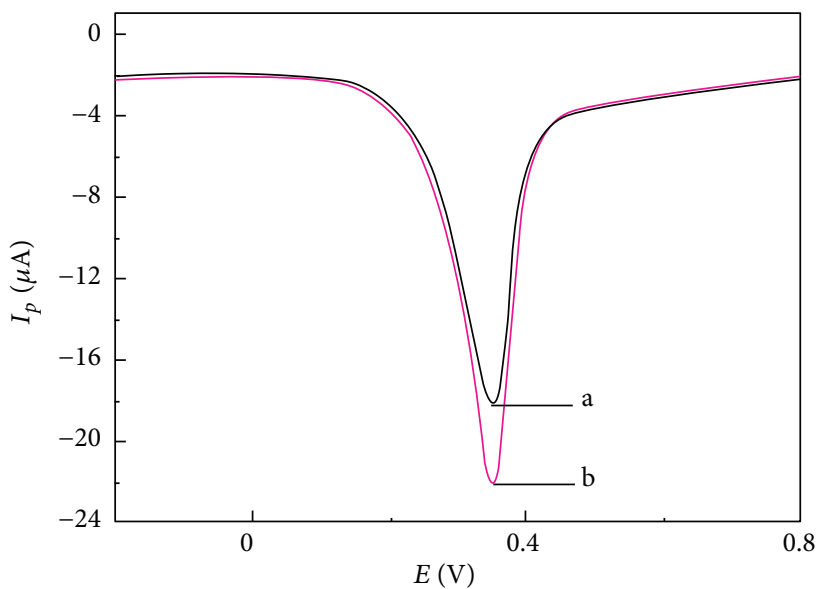

FIgUre 4: DPV for GCE (Curve a) and PLH/GCE (Curve b) for hydroquinone in $\mathrm{H}_{2} \mathrm{SO}_{4}$ solution.

Therefore, poly-L-histidine modified electrodes improve the response of hydroquinone and can be used for sensitive detection of hydroquinone.

$\mathrm{H}_{2} \mathrm{SO}_{4}(\mathrm{pH}=3.0)$ solution contains $1.0 \times 10^{-4} \mathrm{~mol} / \mathrm{L}$ hydroquinone. Potential range: $-0.6 \mathrm{~V} \sim+1.0 \mathrm{~V}$; scanning speed: $100 \mathrm{mV} / \mathrm{s}$ (Figure 3 ).

$\mathrm{H}_{2} \mathrm{SO}_{4}(\mathrm{pH}=3.0)$ solution contains $1.0 \times 10^{-4} \mathrm{~mol} / \mathrm{L}$ hydroquinone. Potential: $-0.05 \mathrm{~V}$; scanning speed: $100 \mathrm{mV} / \mathrm{s}$ (Figure 4).

\section{Results and Discussion}

\subsection{Optimization of Modified Electrodes}

3.1.1. Selection and Optimization of the $p H$ Value for Decorating Poly-L-Histidine Base Solution. Keep the concentration of histidine unchanged and make a series of $0.1 \mathrm{~mol} / \mathrm{L}$ phosphate buffer solution with different $\mathrm{pH}$ values. Create different modified electrodes with the above solution as the base solution. Use the modified electrodes that we prepared before studying the hydroquinone of same concentration based on cyclic voltammetry. The result is shown in Figure 5. From the figure, we observe that in the range of $\mathrm{pH}=5.0 \sim 8.5$, the response current of the modified electrode to hydroquinone increases gradually at the beginning and decreases when $\mathrm{pH}>$ 7.0. This might be caused by the $\mathrm{pH}$ value which will affect the $\mathrm{NH}_{2}$ and the $\mathrm{COOH}$ of $\mathrm{PLH}$. When the $\mathrm{pH}$ is high, it affects the $\mathrm{COOH}$ part and when the $\mathrm{pH}$ is low, it affects the $\mathrm{NH}_{2}$ part. We will investigate it more in future work. Therefore, we use phosphate buffer solution (PBS) with $\mathrm{pH}=7.0$ as the best base solution for decorating poly-Lhistidine, where we use different phosphate buffer solution as the base solution of histidine to get the modified electrode via electrochemical method.

3.1.2. Optimization of the Amount of Modified Poly-LHistidine. Use phosphate buffer solution with $\mathrm{pH}=7.0$ as the best solution of modified histidine and investigate the cyclic voltammogram lap effects of modified membrane on catalytic properties of hydroquinone. When we use poly-L-histidine 


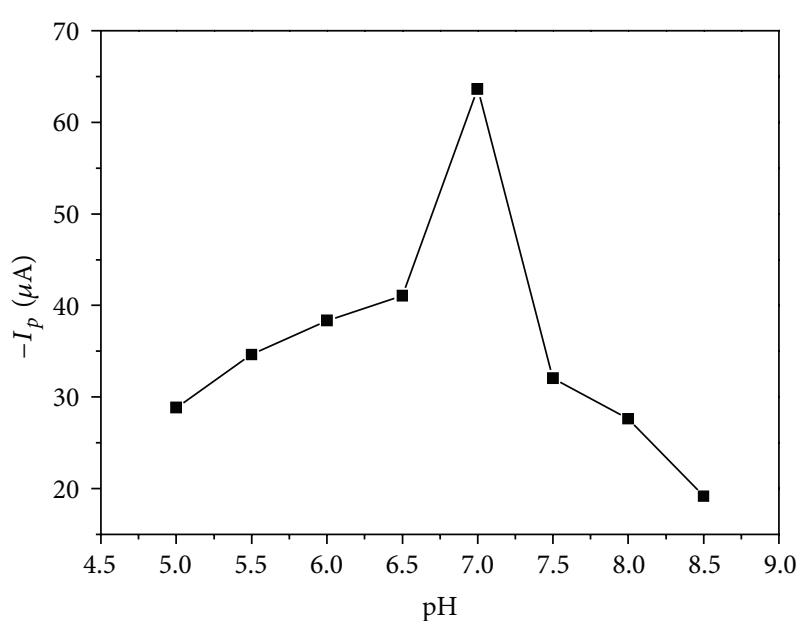

FIGURE 5: The influence of modified electrodes on $1.0 \times 10^{-4} \mathrm{~mol} / \mathrm{L}$ hydroquinone peak current.

modified electrodes with scanning laps of $5,10,15,20$, and 25 to detect hydroquinone, the peak current of modified electrode to hydroquinone increases with the increase of scanning laps. However, when the scanning number is more than 15 , the peak current decreases, which could be caused by the insulation from the membrane itself or losing of certain quantum size effect [20] of the 3D molecular structure; this effect will be examined in another paper. For now, we just choose the poly-L-histidine modified electrodes with circular scanning of 15 laps.

3.1.3. Selection and Optimization of Scanning Speed. In the process of making poly-L-histidine modified electrodes, the scanning speed also plays an important role. We examined how it would affect the electrocatalysis to hydroquinone when using different scanning speeds of $V_{s}=20 \mathrm{mV} / \mathrm{s}$, $25 \mathrm{mV} / \mathrm{s}, 50 \mathrm{mV} / \mathrm{s}, 100 \mathrm{mV} / \mathrm{s}, 150 \mathrm{mV} / \mathrm{s}$, and $180 \mathrm{mV} / \mathrm{s}$. As can be shown in Figure 6, when the scanning speed is $50 \mathrm{mV} / \mathrm{s}$, the peak current response of modified electrodes to hydroquinone reaches highest value. This may be affected by the sedimentation of poly-L-histidine 3D microstructure and electrochemical molecular dynamics; we plan to change the viscosity of the solution to verify fluid dynamics in future. For now, we just choose the scanning speed of $50 \mathrm{mV} / \mathrm{s}$ to prepare poly-L-histidine modified electrodes, where scannings are done on hydroquinone (both to be $1.0 \times 10^{-4} \mathrm{~mol} / \mathrm{L}$ ) with the same concentration, potential range: $-0.6 \sim 1.0 \mathrm{~V}$.

\subsection{Cyclic Voltammetric Behavior of Hydroquinone on Poly-L-Histidine Modified Electrodes}

3.2.1. The Selection and Optimization of $p H$ Value for Supporting Electrolyte. In order to study the electrochemical behavior of hydroquinone on the surface of modified electrodes, we use the poly-L-histidine modified electrodes which were made in the above mentioned optimized condition. We choose $\mathrm{H}_{2} \mathrm{SO}_{4}, \mathrm{HCl}, \mathrm{NH}_{4} \mathrm{Cl}-\mathrm{NH}_{3} \cdot \mathrm{H}_{2} \mathrm{O}, \mathrm{HAc}-\mathrm{NaAc}, \mathrm{KCl}$, phosphate buffer solution $(0.2 \mathrm{~mol} / \mathrm{L})$, and other supporting electrolytes which contain the same concentration of

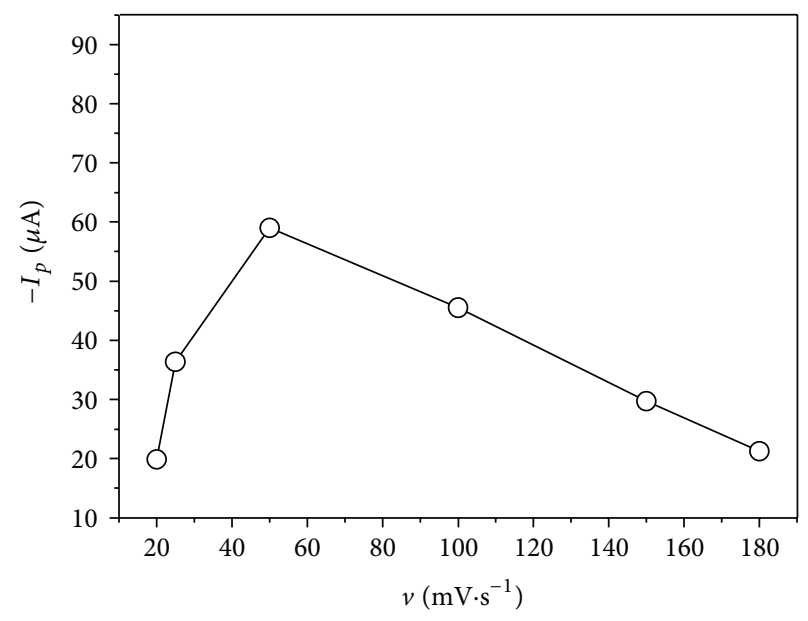

FIGURE 6: Electrocatalysis impact of poly-L-histidine modified electrode with different scanning speed.

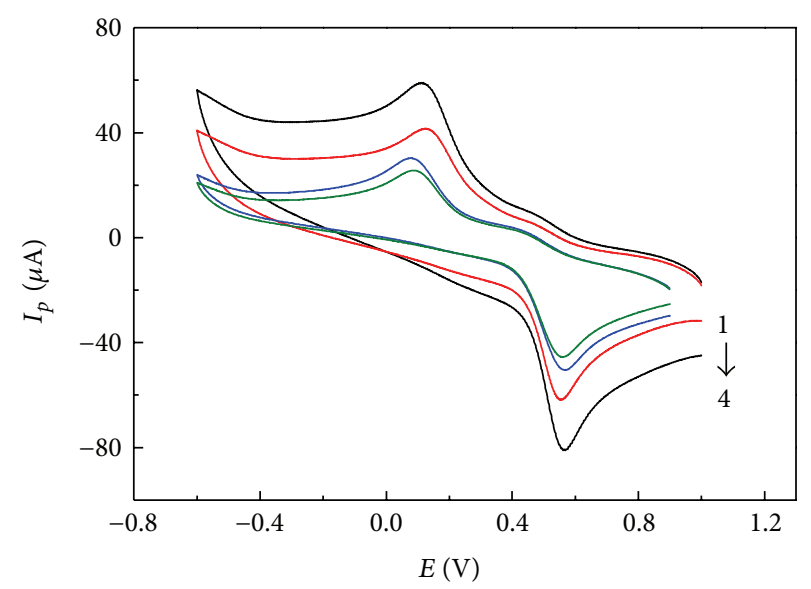

FIGURE 7: Cyclic voltammograms of poly-L-histidine modified electrodes in different $\mathrm{pH}(1.0 \sim 4.0)$ values.

hydroquinone $\left(1.0 \times 10^{-4} \mathrm{~mol} / \mathrm{L}\right)$ to carry out cyclic voltammetric scanning. The result shows that hydroquinone performs the most sensitive peak current response in $\mathrm{H}_{2} \mathrm{SO}_{4}$ solution. This might be caused by the relative right molecular size or associated viscous dynamics. Thus $\mathrm{H}_{2} \mathrm{SO}_{4}$ solution is chosen to be the supporting electrolyte for now. After the determination of the best support electrolyte, we optimize its $\mathrm{pH}$ value. We prepare a series of $\mathrm{H}_{2} \mathrm{SO}_{4}$ solution $(\mathrm{pH}=$ $1.0-4.0)$ in the existence of $1.0 \times 10^{-4} \mathrm{~mol} / \mathrm{L}$ hydroquinone and perform cyclic voltammetry test, respectively. Figure 7 shows the relationship between oxidation peak current of hydroquinone and $\mathrm{pH}$ value. Hydroquinone peak current $I_{P}$ changes along with $\mathrm{pH}$ value. $I_{P}$ value first increases and then decreases when $\mathrm{pH}$ value increases. It reaches the maximum when $\mathrm{pH}=3.0$. This should be caused by the oxygen atoms on ply-L-histidine carboxyl (-COO) and nitrogen atoms on amino group $\left(-\mathrm{NH}_{2}\right)$ via hydrogen bonds to hydroquinone, which activates $\mathrm{OH}$ and weakens $\mathrm{OH}$ bond energy, such that electrons are transferred via $\mathrm{NH} \cdots \mathrm{OH}$ bond and $-\mathrm{COOH} \cdots \mathrm{H}$ bond. When $\mathrm{pH}$ value is low, the concentration of $\mathrm{H}+$ is too high; in this case nitrogen atoms on $-\mathrm{NH}_{2}$ mainly 
exist in the form of $-\mathrm{NH}_{3}{ }^{+}$, which makes it difficult to form hydrogen bonds between electron on $-\mathrm{NH}_{3}{ }^{+}$and $\mathrm{H}$ on $-\mathrm{OH}$ of hydroquinone. When $\mathrm{pH}$ value is too high, it is too easy for hydroquinone to start oxidation reaction; in addition, the $\mathrm{OH}-$ in the solution will attract phenolic hydroxyl, which prevents the formation of hydrogen bonds between nitrogen atoms in poly-L-histidine molecules and phenolic hydroxyl and thus blocks electron transfer, deforms peak shape, reduces peak current, or even makes it disappear. Therefore, we choose $\mathrm{H}_{2} \mathrm{SO}_{4}$ solution with $\mathrm{pH}=3.0$ as the best supporting electrolyte.

The acidic mediator is with the same concentration $(1.0 \times$ $10^{-4} \mathrm{~mol} / \mathrm{L}$ ) of hydroquinone. Curve 1 is acidic mediator solution with $\mathrm{pH}=1.0$; Curve 2 is acidic mediator solution with $\mathrm{pH}=2.0$; Curve 3 is acidic mediator with $\mathrm{pH}=4.0$; Curve 4 is acidic mediator with $\mathrm{pH}=3.0$. Scanning speed: $100 \mathrm{mV} / \mathrm{s}$; scanning potential: $-0.6 \mathrm{~V} \sim 1.0 \mathrm{~V}$.

3.2.2. Optimization of Preaccumulation Potential and Accumulation Time. The accumulation potential and accumulation time directly affect the accuracy and sensitivity of the quantitative measurement. This experiment is based on differential pulse voltammetry (DPV) method and is operated in the solution which contains $1.0 \times 10^{-4} \mathrm{~mol} / \mathrm{L}$ hydroquinone and uses $\mathrm{H}_{2} \mathrm{SO}_{4}$ with $\mathrm{pH}=3.0$ as the support base solution. It examines the influence of hydroquinone accumulation potential on oxidation peak current when the potential is of $-0.06 \mathrm{~V} \sim 1.0 \mathrm{~V}$. The research shows that the peak current changes with the change of accumulation potential. When the accumulation potential is $-0.05 \mathrm{~V}$, it reaches the maximum. Thus we choose $-0.05 \mathrm{~V}$ as the best accumulation. Accumulation time is optimized when fixed accumulation potential is $-0.05 \mathrm{~V}$, and mixing accumulation time is inspected in the range of $5 \mathrm{~s}$ to $40 \mathrm{~s}$. Figure 8 shows that with increase of accumulation time, the oxidation peak current of hydroquinone also increases; then the increasing speed slows when accumulation time reaches $15 \mathrm{~s}$. It keeps constant when the time increases from $20 \mathrm{~s}$ to $40 \mathrm{~s}$, which indicates that the accumulation of hydroquinone has reached saturation. Therefore, we set the accumulation time to $20 \mathrm{~s}$ in the experiment. The reason that poly-L-hydroquinone accumulates so fast is because it contains two hydroxyl groups, which increases the speed of combining with membrane electrodes.

The accumulation potential: $-0.05 \mathrm{~V}$; scanning speed: $100 \mathrm{mV} / \mathrm{S}$.

3.2.3. Relationship between Scanning Rate and Peak Current. We use the poly-L-histidine modified electrode prepared in the optimum condition and $\mathrm{H}_{2} \mathrm{SO}_{4}$ solution with $\mathrm{pH}=3.0$ as supporting electrolyte to test $1.0 \times 10^{-4} \mathrm{~mol} / \mathrm{L}$ hydroquinone solution based on cyclic voltammetry. The experiment examines how hydroquinone peak current responds to poly-L-histidine modified electrode. The result is shown in Figure 9. We can observe that the oxidation peak current of hydroquinone increases with the increasing of scanning rate. In addition, there is a linear relationship between the peak current and scanning rate. The result shows the reaction of hydroquinone on poly-L-histidine modified electrode is controlled by adsorption.

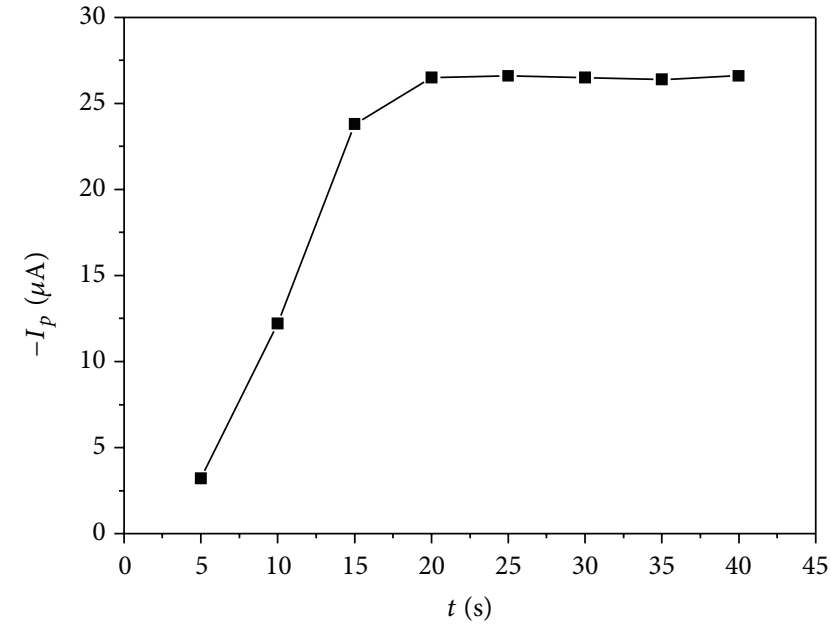

FIGURE 8: Influence of different accumulation time on peak current of hydroquinone $\left(1.0 \times 10^{-4} \mathrm{~mol} / \mathrm{L}\right)$.

The supporting base solution is $\mathrm{H}_{2} \mathrm{SO}_{4}$ with $\mathrm{pH}=3.0$ and hydroquinone $\left(1.0 \times 10^{-4} \mathrm{~mol} / \mathrm{L}\right)$; scanning rate is $V_{\text {sr }}=$ $100-350 \mathrm{mV} / \mathrm{s}$.

3.3. Linear Range and Limit of Detection. Under the optimum condition, we first accumulate hydroquinone for $20 \mathrm{~s}$ and fix the accumulation potential at $-0.05 \mathrm{~V}$. Then we select the different pulse voltammetry for the quantitative determination of hydroquinone. The result shows that the hydroquinone oxidation peak current on poly-L-histidine modified electrode has a linear relationship with the concentration for given scanning rate, as can be seen in Figure 10. The linear function is

$$
-I_{p}(\mu \mathrm{A})=0.381+0.0251 * C\left(\mu \mathrm{mol} \cdot \mathrm{L}^{-1}\right) .
$$

The correlation coefficient $R$ is 0.9968 and detection limit can reach $7.2 \times 10^{-7} \mathrm{~mol} / \mathrm{L}$ for this set of rate.

Based on this set of experiments, we can forecast that if we keep increasing the scanning rate, the final peak current limit by the linear shifting model

$$
\Delta\left(I_{p}\right)(\mu \mathrm{A})=-9.0 e-7 *\left(\frac{V_{\text {sr }}}{50}\right)(\mathrm{mV} / \mathrm{s})+9.2 e-6=0
$$

and by solving the above equation, we obtain the final scanning speed limit of $500 \mathrm{mV} / \mathrm{s}$ and the remaining current limit of $0.2 \mu \mathrm{A}$. This corresponds to the chemical detection limit at $2.0 \times 10^{-7} \mathrm{~mol} / \mathrm{L}$ by the prediction method for this substance, where $\Delta\left(I_{p}\right)$ is the amount of peak difference between consecutive scans; the total number of calibration scannings can be reduced when the amount of shifting $\Delta(E / V)$ is noticeable, for example, $>3 \mathrm{mV}$, where the step size is $50 \mathrm{mV} / \mathrm{s}$.

3.4. Stability and Reproducibility. After the measurement, set the poly-L-histidine modified electrode in $0.1 \mathrm{~mol} / \mathrm{L}$ phosphate buffer solution $(\mathrm{pH}=7.0)$ and stir for $60 \mathrm{~s}$ for electrode updating. Then continuously measure the same hydroquinone solution for 10 times and keep the reduction of 


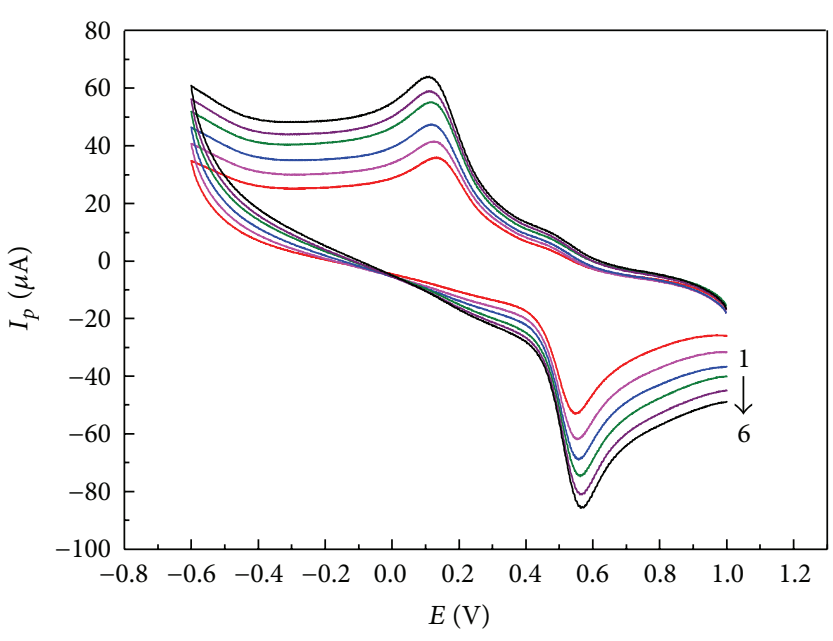

(a)

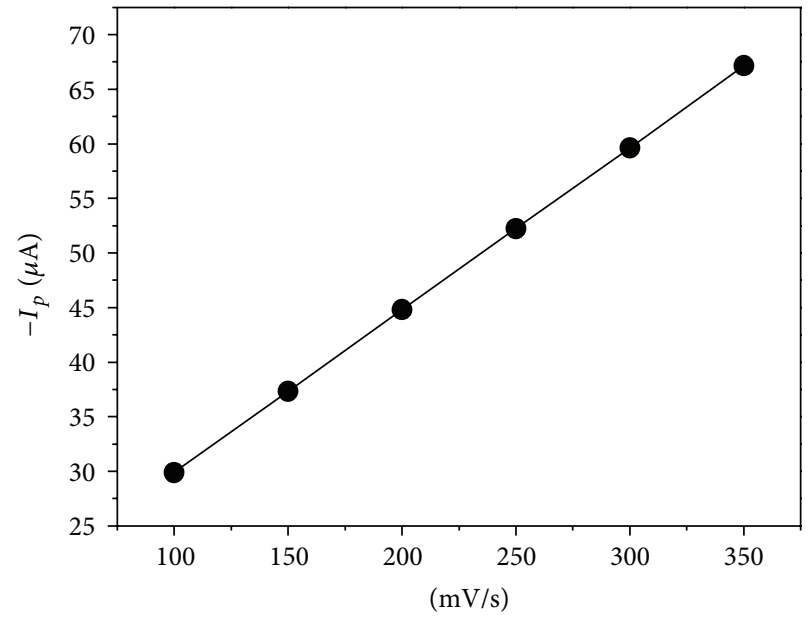

(b)

FIGURE 9: (a) Cyclic voltammograms under different scanning rate; (b) relation curve between hydroquinone peak current and scanning rate.

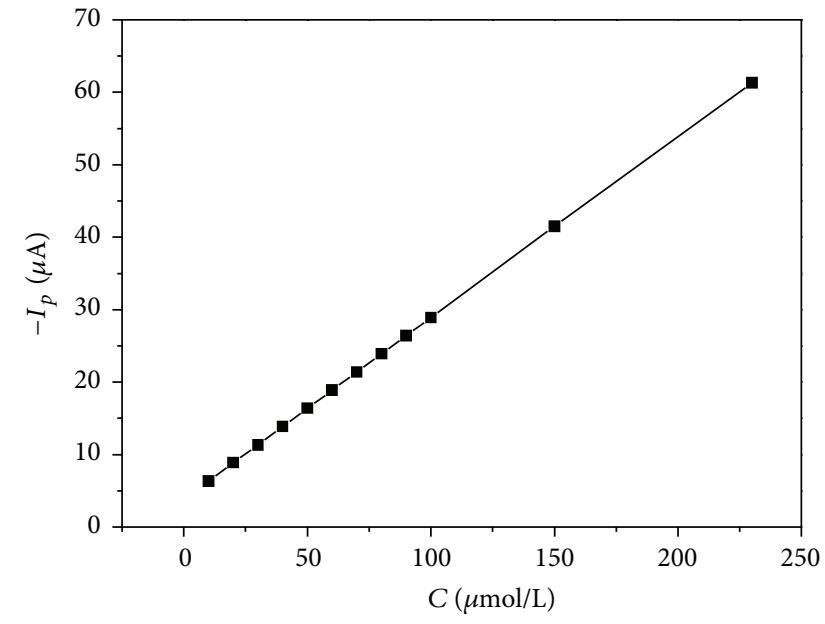

FIGURE 10: Standard curve of hydroquinone.

peaking current below $8.0 \%$ and relative standard deviation (RSD) with $2.0 \%$.

3.5. Sample Determination. Take two factory waste water samples without pretreatment and add them directly into $\mathrm{H}_{2} \mathrm{SO}_{4}$ electrolyte. Adjust the $\mathrm{pH}$ value to 3.0 and measure them using differential pulse voltammetry under optimized condition. Each water sample was measured three times. The result is shown in Table 1.

\section{Conclusion and Future Work}

In this work, we use carefully selected electrochemical procedure to modify the poly-L-histidine onto the glassy carbon electrode, which is then successfully applied to determine the presence of the hydroquinone in waste water. Both the oxygen atoms on poly-L-histidine carboxyl (-COO) and nitrogen atoms on amino $\left(-\mathrm{NH}_{2}\right)$ of poly-L-histidine modified electrodes produce hydrogen adsorption via hydrogen
TABLE 1: Result of hydroquinone determination $(n=3)$.

\begin{tabular}{lccc}
\hline $\begin{array}{l}\text { Sample } \\
\text { number }\end{array}$ & $\begin{array}{c}\text { Content of 1,4-HQ } \\
(\mathrm{mmol} / \mathrm{L})\end{array}$ & $\begin{array}{c}\text { Mean } \\
(\mathrm{mmol} / \mathrm{L})\end{array}$ & $\begin{array}{c}\text { UV } \\
\text { spectroscopy } \\
(\mathrm{mmol} / \mathrm{L})\end{array}$ \\
\hline \multirow{2}{*}{1} & 1.3482 & & \\
& 1.3465 & 1.3483 & 1.3479 \\
& 1.3502 & & \\
2 & 0.9588 & & 0.9513 \\
& 0.9562 & 0.9576 & \\
\hline
\end{tabular}

bonding with the hydrogen of hydroquinone. Thus the trace of hydroquinone shows good selectivity and high sensitivity, and we obtain satisfactory result in the experiment. We also noticed that the oxidizing current peak value and voltage position demonstrated some diminishing shifting patterns, by which we can predict the ultimate trace limitation of our method; for future work, we will examine if this particular shifting pattern is the signature between the hydroquinone and the poly-L-histidine or solely from the microstructure of the poly-L-histidine membrane; if it is the former, we will further investigate the potential bonding mechanism between hydroquinone and histidine that blocks histidine from passing the biological signal across the stem cells, and eventually causing the cancer; if it is the latter, we will also examine the potential quantum dot dynamic effect from the nanometer poly-L-histidine structure; then we will be trying to increase the sensitivity further by changing either the viscosity of solution or the shape of the electrode, to favor the peaking condition.

\section{Conflict of Interests}

The authors declare that there is no conflict of interests regarding the publication of this paper. 


\section{References}

[1] Y. Zhang, H. Zhuang, and H. Lu, "Electrocatalytic oxidation of hydroquinone at poly(crystal-violet) film-modified electrode and its selective determination in the presence of ohydroquinone and m-hydroquinone," Analytical Letters, vol. 42, no. 2, pp. 339-351, 2009.

[2] W. Thogchai and B. Liawruangrath, "Micellar liquid chromatographic determination of arbutin and hydroquinone in medicinal plant extracts and commercial cosmetic products," International Journal of Cosmetic Science, vol. 35, no. 3, pp. 257-263, 2013.

[3] Y. Ibuki and R. Goto, "Dysregulation of apoptosis by benzene metabolites and their relationships with carcinogenesis," Biochimica et Biophysica Acta-Molecular Basis of Disease, vol. 1690, no. 1, pp. 11-21, 2004.

[4] H. Terasaka, S. R. M. D. Morshed, K. Hashimoto, H. Sakagami, and S. Fujisawa, "Hydroquinone-induced apoptosis in HL-60 cells," Anticancer Research, vol. 25, pp. 161-170, 2005.

[5] Y. Zhang and Z. Ma, "Electrochemical behavior of hydroquinone at poly (acridine orange)-modified electrode and its separate detection in the presence of o-hydroquinone and m-hydroquinone," Analytical Letters, vol. 39, no. 7, pp. 12891298, 2006.

[6] P. J. Kerzic, W. S. Liu, M. T. Pan et al., "Analysis of hydroquinone and catechol in peripheral blood of benzene-exposed workers," Chemico-Biological Interactions, vol. 184, no. 1-2, pp. 182-188, 2010.

[7] W. Gao and C. Legido-Quigley, "Fast and sensitive high performance liquid chromatography analysis of cosmetic creams for hydroquinone, phenol and six preservatives," Journal of Chromatography A, vol. 1218, no. 28, pp. 4307-4311, 2011.

[8] B. Haghighi and R. Dadashvand, "Flow injection chemiluminescence analysis of phenolic compounds using the NCSluminol system," Analytical and Bioanalytical Chemistry, vol. 384, no. 5, pp. 1246-1253, 2006.

[9] R. A. Issa, F. U. Afifi, and B. I. Amro, "Studying the anti-tyrosinase effect of Arbutus andrachne L. extracts", International Journal of Cosmetic Science, vol. 30, no. 4, pp. 271-276, 2008.

[10] E. S. Elzanfaly, A. S. Saad, and A.-E. B. Abd-Elaleem, "Simultaneous determination of retinoic acid and hydroquinone in skin ointment using spectrophotometric technique (ratio difference method)," Saudi Pharmaceutical Journal, vol. 20, no. 3, pp. 249253, 2012.

[11] R. Jogarami, P. Jain, and S. Sharma, "Validated UV spectrophotometric method development for simultaneous estimation of tazarotene and hydroquinone in gel preparation," Journal of Pharmacy Research, vol. 5, no. 4, pp. 2273-2275, 2012.

[12] Y. Ni, Z. Xia, and S. Kokot, "A kinetic spectrophotometric method for simultaneous determination of phenol and its three derivatives with the aid of artificial neural network," Journal of Hazardous Materials, vol. 192, no. 2, pp. 722-729, 2011.

[13] M. Pistonesi, M. E. Centurión, M. Pereyra, A. G. Lista, and B. S. F. Band, "Synchronous fluorescence for simultaneous determination of hydroquinone and resorcinol in air samples," Analytical and Bioanalytical Chemistry, vol. 378, no. 6, pp. 1648-1651, 2004.

[14] S. J. Humphrey and D. W. Pratt, "High resolution $S_{1} \leftarrow S_{0}$ fluorescence excitation spectra of hydroquinone-distinguishing the cis and trans rotamers by their nuclear spin statistical weights," The Journal of Chemical Physics, vol. 99, no. 7, pp. 5078-5086, 1993.
[15] J. Yano, "Electrode reactions of several dissolved hydroquinones on a polyaniline-modified electrode and what occurs in the polyaniline," Surface \& Coatings Technology, vol. 231, pp. 234238, 2013.

[16] X. Ma, Z. Liu, C. Qiu, T. Chen, and H. Ma, "Simultaneous determination of hydroquinone and catechol based on glassy carbon electrode modified with gold-graphene nanocomposite," Microchimica Acta, vol. 180, no. 5-6, pp. 461-468, 2013.

[17] P. Raghu, T. M. Reddy, K. Reddaiah, L. R. Jaidev, and G. Narasimha, "A novel electrochemical biosensor based on horseradish peroxidase immobilized on Ag-nanoparticles/poly(1arginine) modified carbon paste electrode toward the determination of pyrogallol/hydroquinone," Enzyme and Microbial Technology, vol. 52, no. 6-7, pp. 377-385, 2013.

[18] B. Fang, J. Sun, G. Wang, Y. Yu, and S. Jiao, "Preparation and application of $\mathrm{La}(\mathrm{OH})_{3}$ nanoparticles self-assembled film modified electrode," Analytical Letters, vol. 40, no. 4, pp. 705-714, 2007.

[19] S. Sundaram and S. K. Annamalai, "Selective immobilization of hydroquinone on carbon nanotube modified electrode via phenol electro-oxidation method and its hydrazine electro-catalysis and Escherichia coli antibacterial activity," Electrochimica Acta, vol. 62, pp. 207-217, 2012.

[20] S. John and B. Erkki, Advances in Quantum Chemistry, Academic Press, 1st edition, 2012. 

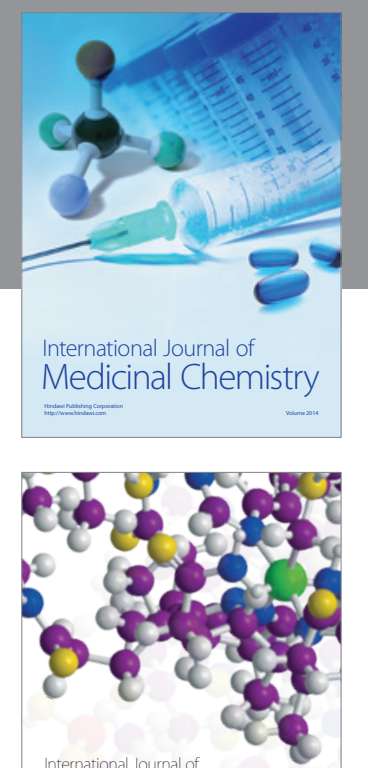

\section{Carbohydrate} Chemistry

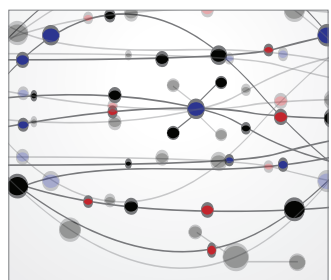

The Scientific World Journal
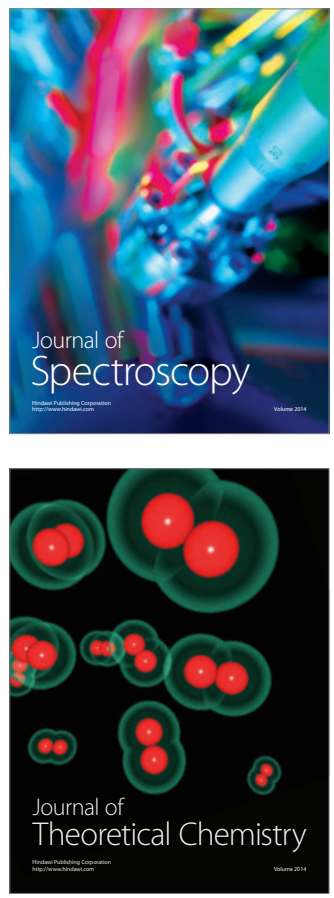
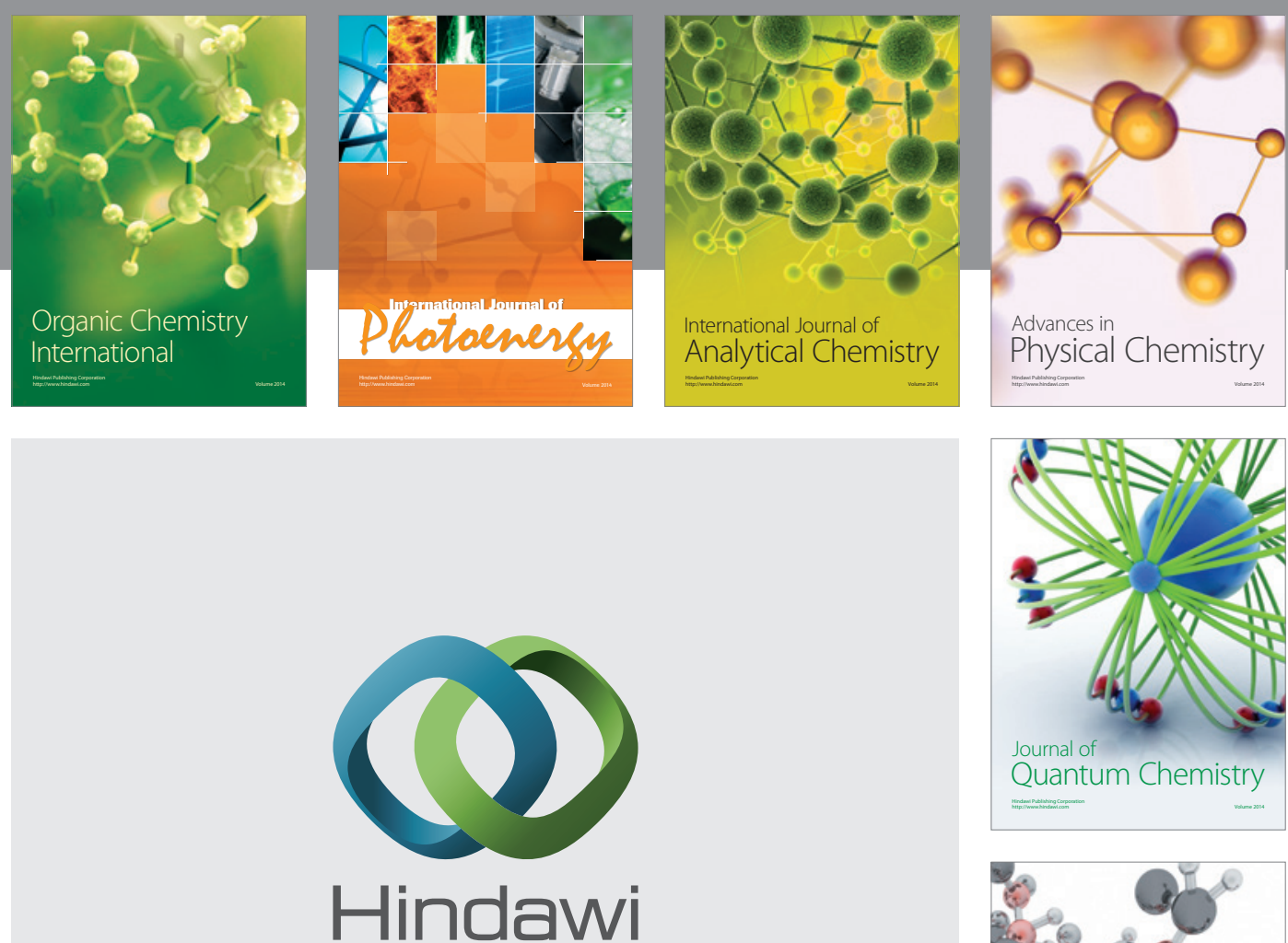

Submit your manuscripts at

http://www.hindawi.com

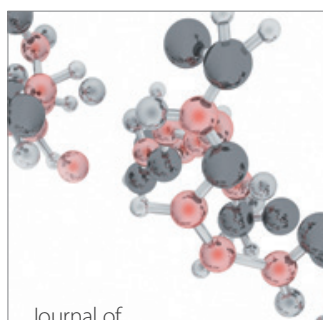

Analytical Methods

in Chemistry

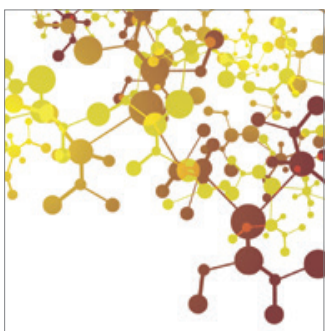

Journal of

Applied Chemistry

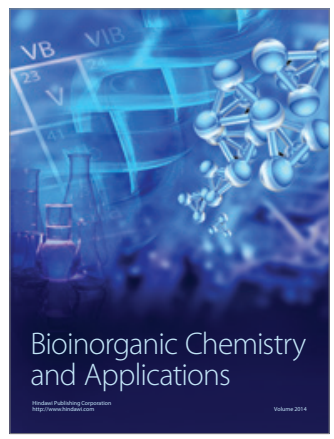

Inorganic Chemistry
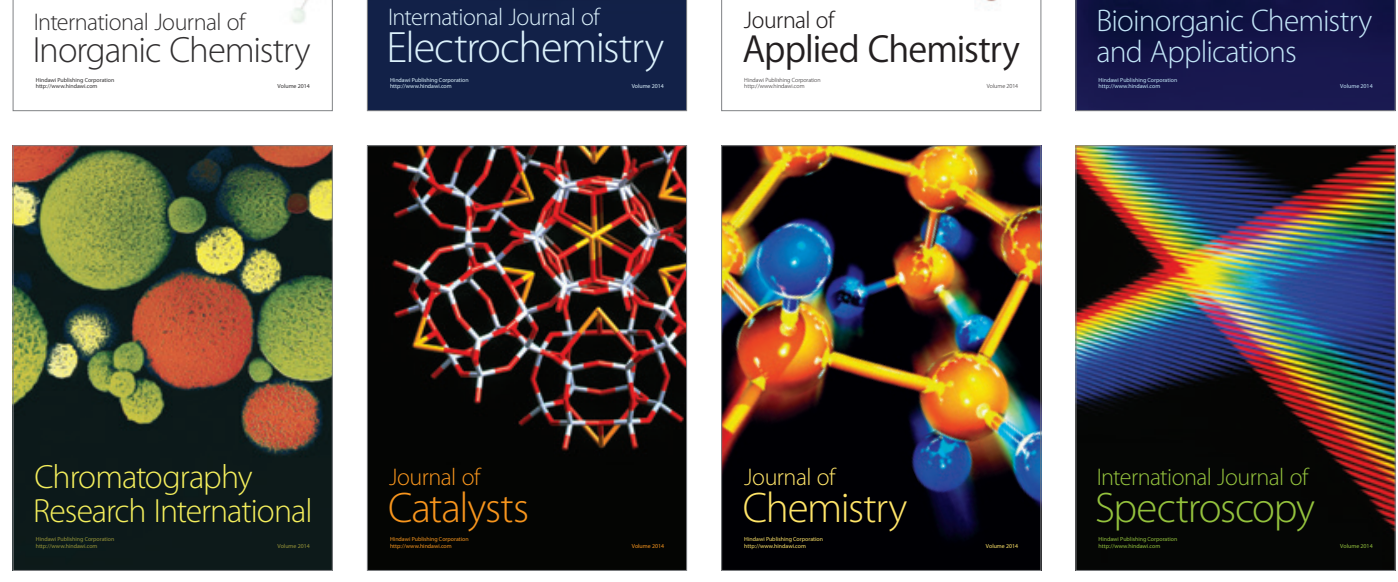